\title{
Activating transcription factor 5 enhances radioresistance and malignancy in cancer cells
}

\author{
Seiichiro Ishihara ${ }^{1,2}$, Motoaki Yasuda ${ }^{3}$, Akihiro Ishizu$^{4}$, Masayori Ishikawa ${ }^{5}$, \\ Hiroki Shirato ${ }^{6}$, Hisashi Haga ${ }^{1,2}$ \\ ${ }^{1}$ Faculty of Advanced Life Science, Hokkaido University, Kita-ku, Sapporo 060-0810, Japan \\ ${ }^{2}$ Research Center for Cooperative Projects, Graduate School of Medicine, Hokkaido University, Kita-ku, Sapporo 060-8638, \\ Japan \\ ${ }^{3}$ Department of Oral Pathobiological Science, Graduate School of Dental Medicine, Hokkaido University, Kita-ku, Sapporo \\ 060-8586, Japan \\ ${ }^{4}$ Division of Medical Laboratory Science, Faculty of Health Sciences, Hokkaido University, Kita-ku, Sapporo 060-0812, Japan \\ ${ }^{5}$ Department of Medical Physics, Graduate School of Medicine, Hokkaido University, Kita-ku, Sapporo 060-8638, Japan \\ ${ }^{6}$ Department of Radiology, Graduate School of Medicine, Hokkaido University, Kita-ku, Sapporo 060-8638, Japan
}

Correspondence to:

Hisashi Haga, e-mail: haga@sci.hokudai.ac.jp

Keywords: Activating transcription factor 5, radioresistance, cell growth, cell invasion, cancer cells

Received: November 04, $2014 \quad$ Accepted: December 11, $2014 \quad$ Published: February 17, 2015

\section{ABSTRACT}

Radiotherapy is effective for treating various types of tumors. However, some cancer cells survive after irradiation and repopulate tumors with highly malignant phenotypes that correlate with poor prognosis. It is not known how cancer cells survive and generate malignant tumors after irradiation. Here, we show that activating transcription factor 5 (ATF5) promotes radioresistance and malignancy in cancer cells after irradiation. In the G1-S phase of the cell cycle, cancer cells express high levels of ATF5, which promotes cell cycle progression and thereby increases radioresistance. Furthermore, ATF5 increases malignant phenotypes, such as cell growth and invasiveness, in cancer cells in vitro and in vivo. We have identified a new mechanism for the regeneration of highly malignant tumors after irradiation and shown that ATF5 plays a key role in the process.

\section{INTRODUCTION}

Radiotherapy is effective for treating various types of tumors [1]. However, some cancer cells survive after irradiation and repopulate tumors with highly malignant phenotypes, such as high proliferative ability and invasiveness, which correlate with poor prognosis [2-5]. As shown in our previous studies, lung cancer cells that survive irradiation acquire invasive ability that is dependent on cell-matrix adhesion regulated by integrin $\beta 1$, cellular contractile force modulated by myosin regulatory light chain (MRLC), and molecular signaling mediated by epidermal growth factor receptor and other molecules [6-8]. However, it is not known how cancer cells survive and generate highly malignant tumors after irradiation.
Activating transcription factor 5 (ATF5, also referred to as ATFx) is a member of the ATF/cAMP response element-binding family of transcription factors [9-11]. ATF5 regulates the differentiation of neural progenitor cells and adipose-derived stem cells $[12,13]$. Moreover, ATF5 is expressed at higher levels in neural and breast cancer cells than in the respective non-cancerous cells $[14,15]$. Repression of ATF5 induces apoptotic cell death in neural and breast cancer cells but does not kill non-transformed cells. Our group previously reported that ATF5 increases radioresistance and motility in mouse fibrosarcoma cells [16]. These findings suggest that ATF5 is a key molecule for cancer cell survival and malignancy after irradiation. Therefore, in this study, we investigated the role of ATF5 in radioresistance and in the development of malignant phenotypes in human cancer cells after irradiation. 


\section{RESULTS}

\section{ATF5 enhances radioresistance}

First, we investigated whether ATF5 regulates radioresistance in human cancer cells. We transfected the ATF5 gene into subclonal A549 human lung adenocarcinoma cells $(\mathrm{P})$ and established subclonal $\mathrm{P}$ cells overexpressing ATF5 (P-ATF5(1) and P-ATF5(2) cells). ATF5 overexpression in these cell lines was confirmed with western blotting (Figure 1A). We then evaluated radioresistance in the cells by counting the number of colonies generated by cells that survived irradiation. The colony number in P-ATF5(1) and (2) cells 12 days after 10-Gy irradiation was greater than that in P cells (Figure 1B). The number of colonies after irradiation did not differ remarkably between $\mathrm{P}$ and subclonal P cells overexpressing AG-CAAX (P-CAAX was the negative control; Supplementary Figure S1A, S1B). On the other hand, the colony number 12 days after seeding in the absence of irradiation was similar in the three cell lines (Supplementary Figure S2A). Colony formation by $\mathrm{P}$ and P-CAAX cells was similar under non-irradiated conditions (Supplementary Figure S1C). These results indicate that ATF5 enhances radioresistance but does not regulate colony formation itself in A549 lung adenocarcinoma cells.

\section{The cell cycle decides ATF5 expression}

Next, we determined whether ATF5 was consistently expressed in each cell line and whether ATF5 expression changed under specific conditions. We hypothesized that ATF5 expression varies with the cell cycle because previous reports have indicated that radioresistance changes depending on the cell cycle phase [17-20]. Therefore, we analyzed ATF5 expression in P cells synchronized with nocodazole treatment [21]. After nocodazole washout, the cells expressed cell cycle markers for specific cell cycle phases, indicating that cell cycle synchronization was successful (Figure 1C, 1D and Supplementary Figure S3A): cyclin B1, cyclin D1, cyclin
A

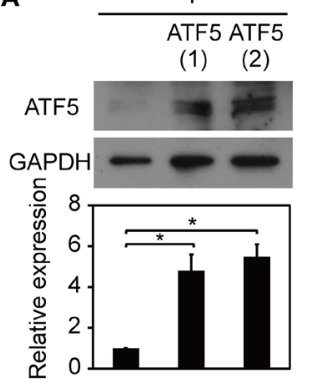

B

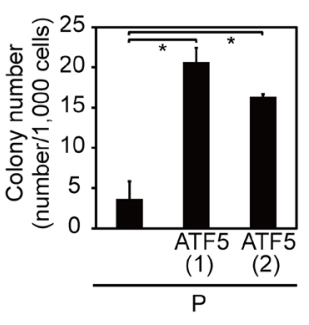

E

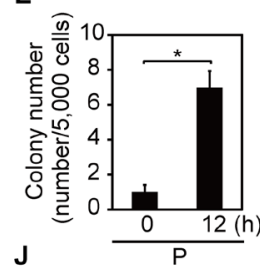

$\mathrm{J}$
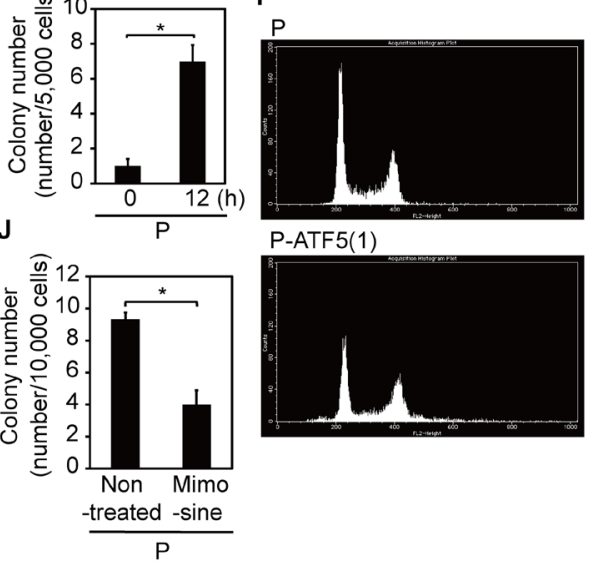

P-ATF5(1)

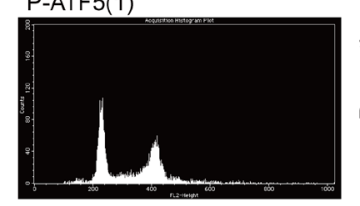

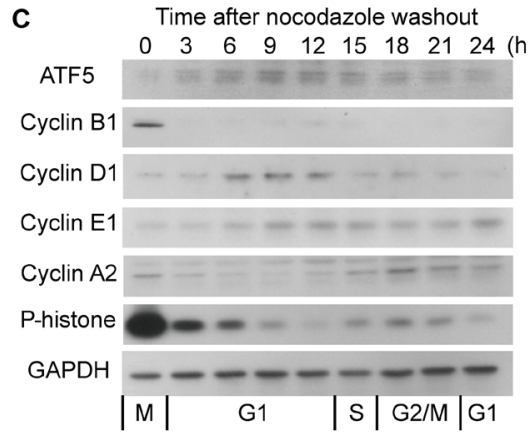

G $\quad$ H
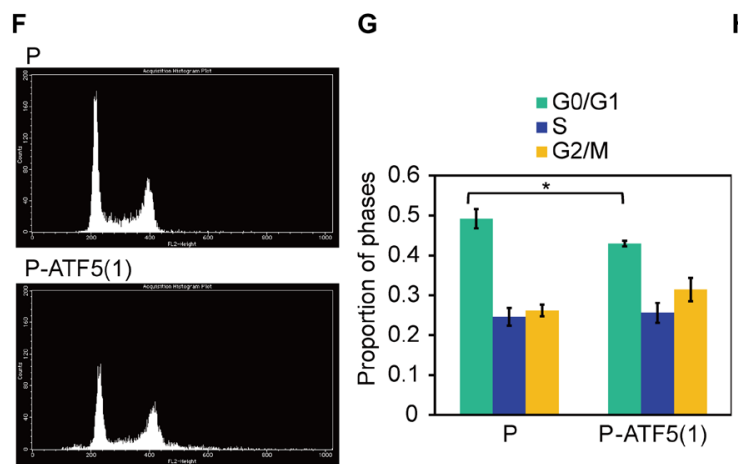
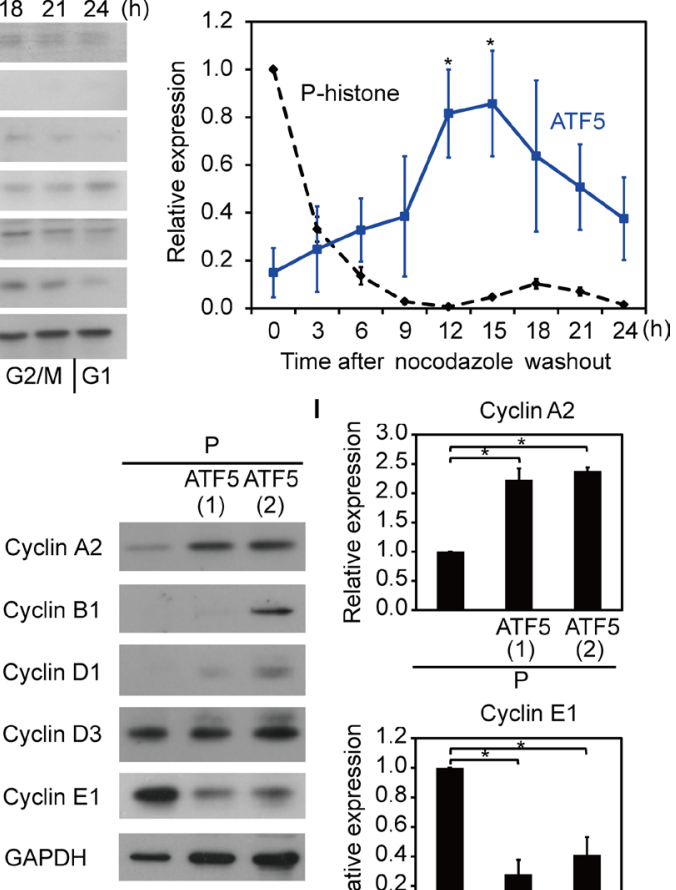

I

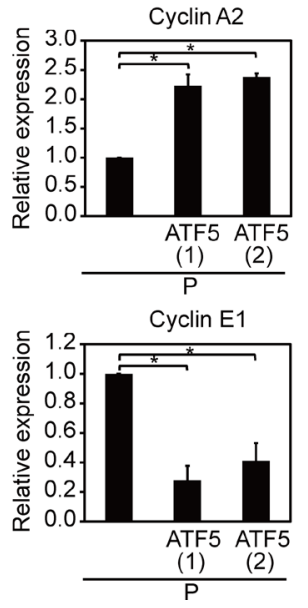

Figure 1: ATF5 enhances radioresistance by promoting cell cycle progression. (A) Western blot of ATF5 and GAPDH. The graph shows the relative expression of ATF5. P: subclonal A549 cells. P-ATF5(1), (2): subclonal P cells overexpressing ATF5. (B) Colony number after irradiation. (C) Western blot of ATF5, cell cycle-regulated genes, and GAPDH in synchronized P cells. The numbers indicate the time after nocodazole washout. (D) Relative expression of ATF5 and P-histone in C. (E) Colony number of P cells after irradiation. The cells were irradiated after cell cycle synchronization. The horizontal axis indicates the time after nocodazole washout. (F) Flow cytometry of cells stained with propidium iodide. (G) Relative proportion of cells in the cell cycle phases determined by F. Error bars $=$ s.e.m. from 3 (P) or 4 (P-ATF5(1)) independent experiments. (H) Western blot of cyclin and GAPDH. (I) Relative expression of cyclin A2 and cyclin E1 in H. (J) Colony number of $\mathrm{P}$ cells treated or not treated with mimosine after irradiation. ${ }^{*} P<0.05$. Error bars $=$ s.e.m. from 3 independent experiments except $\mathrm{G}$. 
E1, cyclin A2, and P-histone indicated G2-M, G1, G1-S, $\mathrm{S}-\mathrm{M}$, and $\mathrm{M}$ phases, respectively [22, 23]. ATF5 was highly expressed from late G1 phase to $\mathrm{S}$ phase (Figure 1C, 1D and Supplementary Figure S3A). Thus, ATF5 is not consistently expressed but changes according to the cell cycle phase in cancer cells.

Because ATF5 expression was dependent on the cell cycle phase, we next investigated whether radioresistance was dependent on the cell cycle. We compared synchronized cells in late G1 phase (obtained $12 \mathrm{~h}$ after nocodazole washout) that displayed high ATF5 expression with synchronized cells in M phase (obtained $0 \mathrm{~h}$ after nocodazole washout) that showed low ATF5 expression (Figure 1C, 1D and Supplementary Figure S2). The cells irradiated $12 \mathrm{~h}$ after nocodazole washout had higher radioresistance than the cells irradiated $0 \mathrm{~h}$ after nocodazole washout (Figure 1E). Colony formation by the two synchronized cell populations was similar under nonirradiated conditions (Supplementary Figure S2B). Thus, ATF5 expression and radioresistance are dependent on the cell cycle in cancer cells.

\section{ATF5 promotes cell cycle progression}

To understand the mechanism underlying radioresistance, we investigated how ATF5 regulates radioresistance. We hypothesized that ATF5 enhances radioresistance via regulation of the cell cycle because ATF5 expression was dependent on the cell cycle (Figure 1C, 1D and Supplementary Figure S3A, S3B, S3C). The proportion of P-ATF5(1) cells in G0/G1 phase was lower than the proportion of $\mathrm{P}$ cells in G0/G1 phase (Figure 1F, 1G). In contrast, the proportion of P-CAAX cells in the G0/ G1 phase was higher than that in P cells (Supplementary Figure S1D). Combined with results showing that ATF5 was highly expressed during late $\mathrm{G} 1$ to $\mathrm{S}$ phase (Figure 1C, 1D and Supplementary Figure S3A, S3B, S3C), the finding indicates that ATF5 promotes $\mathrm{G} 1 / \mathrm{S}$ transition at late G1 phase. Indeed, P-ATF5(1) and (2) cells expressed high levels of cyclin A2, a marker of S-M phases, and low levels of cyclin E1, a marker of G1-S phases, when compared to P cells (Figure 1H, 1I), whereas there were no remarkable differences in the expression of cyclin A2 and cyclin E1 between P and P-CAAX cells (Supplementary Figure S1E). We then examined radioresistance when the G1/S transition was inhibited with mimosine treatment [24]. Mimosine treatment increased the proportion of $\mathrm{G} 0 /$ G1 phase cells, reduced the number of G2/M phase cells, and suppressed cyclin A2 expression (Supplementary Figure S4A, S4B, S4C, S4D), indicating that the treatment inhibited the $\mathrm{G} 1 / \mathrm{S}$ transition. P cells treated with mimosine had lower radioresistance than control cells, whereas there was no significant difference in colony formation by these cells under non-irradiated conditions (Figure 1J and Supplementary Figure S2C). These results show that ATF5 promotes radioresistance by promoting the $\mathrm{G} 1 / \mathrm{S}$ transition.
Because ATF5 increased the expression of cyclin A2 and repressed the expression of cyclin E1, we determined whether ATF5 regulated radioresistance via the upregulation of cyclin A2 and/or the downregulation of cyclin E1. Downregulation of cyclin E1 repressed radioresistance in $\mathrm{P}$ cells but did not affect colony formation in non-irradiated cells (Supplementary Figure S5A, S5B, S5C). Knockdown of cyclin A2 in P-ATF5(1) cells did not affect radioresistance or affect colony formation in non-irradiated cells (Supplementary Figure S5D, S5E, S5F). Therefore, ATF5 enhances radioresistance independent of cyclin E1 and cyclin A2 expression.

\section{ATF5 enhances malignant phenotypes}

Cancer cells that survive after irradiation acquire malignant phenotypes [2-5]. We previously reported that $P$ cells that survive after irradiation (IR cells) are more invasive than non-irradiated P cells [6-8]. Therefore, we examined the phenotypes of $\mathrm{P}$ and IR cells to determine whether ATF5 promotes malignancy in cancer cells. Cells were cultured in collagen gel-overlay conditions, enabling us to observe tumor-mimic colony formation and cell invasion in a three-dimensional collagen matrix in vitro. In collagen gel-overlay conditions, ATF5 expression was higher in IR cells than in P cells (Figure 2A). Furthermore, the transcriptional activity of cAMP response element (CRE), which is repressed by ATF5 [10], was significantly lower in IR cells than in P cells (Supplementary Figure S6A). In addition, ATF5 repression increased CRE activity in IR cells (Supplementary Figure S6B). These results indicated that ATF5 expression and activity were upregulated in IR cells. ATF5 expression was also higher in P-ATF5(1) and (2) cells than in P cells in collagen gel-overlay conditions (Figure 2B). However, ATF5 expression was similar between $\mathrm{P}$ and P-CAAX cells in collagen gel-overlay conditions (Supplementary Figure $\mathrm{S} 1 \mathrm{~F})$. In collagen gel-overlay conditions, tumor size and cell number in IR, P-ATF5(1), and P-ATF5(2) cells were significantly greater than in P cells (Figure 2C-2E), whereas cell number in $\mathrm{P}$ and P-CAAX cells was similar (Supplementary Figure S1G). Thus, ATF5 enhances the growth of cancer cells in vitro.

We also examined the roles of ATF5 in tumorigenesis and cell growth in vivo. We analyzed tumor number and size after injecting cancer cells into nude mice. A greater number of mice developed tumors after injection of IR, P-ATF5(1), and P-ATF5 (2) cells than after injection of P cells (Figure 2F). Furthermore, tumor volume was significantly larger in mice injected with P-ATF5(1) and (2) cells than in mice injected with $\mathrm{P}$ cells (Figure 2F and Supplementary Figure S7A, S7B). In addition, the proportion of mitotic cells in the tumors was higher after injection of IR, P-ATF5(1), and P-ATF5(2) cells than after injection of $\mathrm{P}$ cells (Supplementary Figure S7C). These results show that ATF5 promotes tumorigenesis and cancer cell growth in vivo. 
A
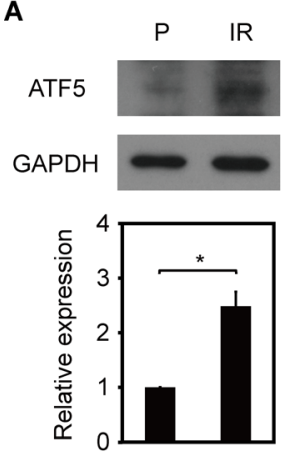

E

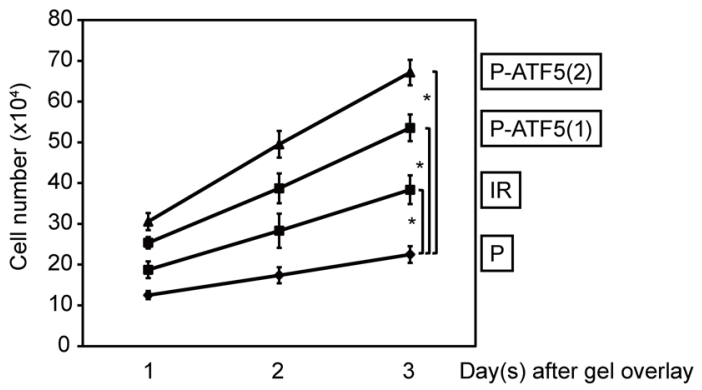

C

$P$

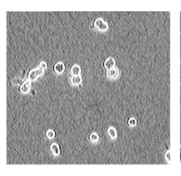

P-ATF5(1)
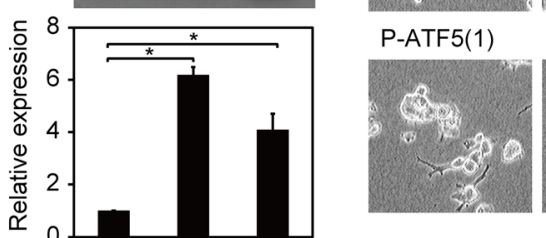

$\mathbf{F}$

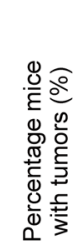

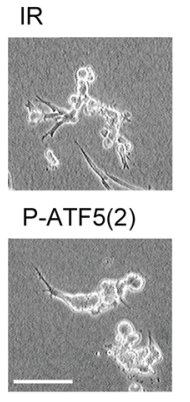
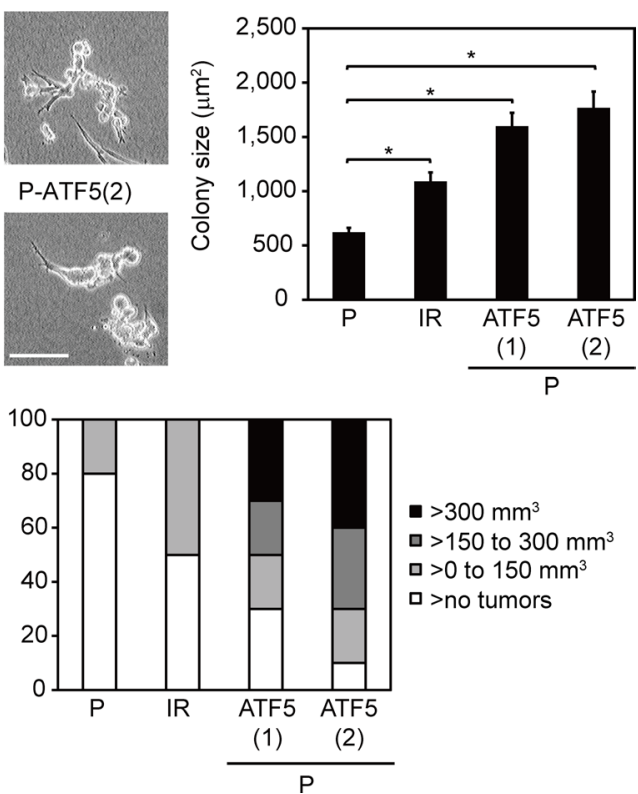

- >300 $\mathrm{mm}^{3}$

$\square>150$ to $300 \mathrm{~mm}^{3}$

a >0 to $150 \mathrm{~mm}^{3}$

$\square>$ no tumors

Figure 2: ATF5 promotes cell growth. (A) Western blot of ATF5 and GAPDH. The graph indicates the relative expression of ATF5. P: subclonal A549 cells. IR: P cells that survived irradiation. (B) Western blot of ATF5 and GAPDH. P-ATF5(1), (2): subclonal P cells overexpressing ATF5. (C) Phase-contrast images. Bar $=200 \mu \mathrm{m}$. (D) Colony size of cells in C. Error bars = s.e.m. from 134 (P), 107 (IR), 143 (P-ATF5(1)), or 155 (P-ATF5(2)) colonies in 3 independent experiments. (E) Number of cells. The horizontal axis indicates the days after collagen gel-overlay. (F) Percentage of mice with tumors. The colors of the bars indicate the tumor volume. $n=10$ mice. ${ }^{*} P<0.05$. Error bars $=$ s.e.m. from 3 independent experiments except D. The cells were cultured in collagen gel-overlay conditions.

We also examined the roles of ATF5 in invasiveness in vitro and in vivo. We downregulated ATF5 expression in IR cells using an RNAi method (Figure 3A) and assessed invasiveness in vitro by analyzing migration in collagen gel-overlay conditions. Relative to P and P-CAAX cells, P-ATF5(1) and (2) cells exhibited higher migratory ability with the generation of protrusions (Figure 3B, 3C, Supplementary Figure S1H, S1I, and Videos S1-S3). In addition, ATF5 downregulation suppressed invasiveness in IR cells (Figure 3B, 3C and Videos S4, S5). Furthermore, tumors generated by IR, P-ATF5(1), and P-ATF5(2) cells in nude mice displayed an invasive front on the border between tumor tissue and normal tissue, whereas tumors generated by P cells did not (Supplementary Figure S7D). Therefore, ATF5 enhances invasiveness in cancer cells in vitro and in vivo.

Previous studies have reported that suppression of ATF5 induces apoptosis in cancerous cells [14, 15]. However, in this study, downregulation of ATF5 did not trigger apoptosis in IR cells (Supplementary Figure S6C). This result suggests that the role of ATF5 in apoptosis induction in cancer cells is dependent on the cell type.

\section{ATF5 induces integrin $\beta 1$ expression}

We previously showed that invasiveness in IR cells is dependent on the activity of integrin $\beta 1$ [6], an adhesion protein that connects the cell surface to extracellular matrices such as collagen [25]. Therefore, we examined whether ATF5 regulates invasiveness via integrin $\beta 1$. The protein expression of integrin $\beta 1$ was greater in P-ATF5(1) and (2) cells than in P and P-CAAX cells in collagen gel-overlay conditions (Figure 4A and Supplementary Figure S1J). In contrast, transient overexpression of ATF5 did not enhance integrin $\beta 1$ expression (Supplementary Figure S8A). Furthermore, mRNA expression of integrin $\beta 1$ was lower in P-ATF5(1) and (2) cells than in P cells (Supplementary Figure S8B). These results suggest that ATF5 does not enhance the transcription of integrin $\beta 1$ mRNA and promotes protein expression of integrin $\beta 1$ by its long-lasting, stable expression. In P and P-CAAX cells, integrin $\beta 1$ was uniformly localized at the cell periphery, whereas integrin $\beta 1$ accumulated at the tips of protrusions in P-ATF5(1) cells (Figure 4B and Supplementary Figure S1K). In addition, ATF5 downregulation in IR cells repressed integrin $\beta 1$ expression in collagen gel-overlay conditions (Figure 4A). Next, we inhibited integrin $\beta 1$ activity in cancer cells using the inhibitory antibody AIIB2 [26] and examined invasiveness. AIIB2 treatment repressed invasiveness in P-ATF5(1) and (2) cells, and washout after AIIB2 treatment restored invasiveness (Figure 4C, 4D and Videos S2, S3). We also quantified cells according to their morphology in collagen gel-overlay conditions. A large number of P-ATF5(1) and (2) cells exhibited spindle morphology, indicative of high invasiveness (Figure 4E, 4F). In contrast, P cells, P-CAAX cells, AIIB2-treated 
A

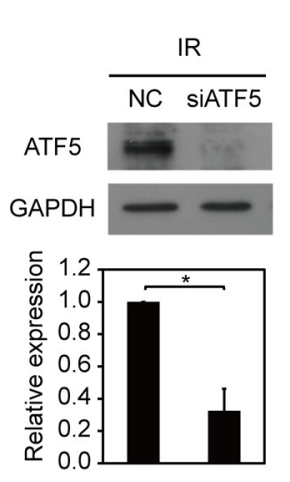

B

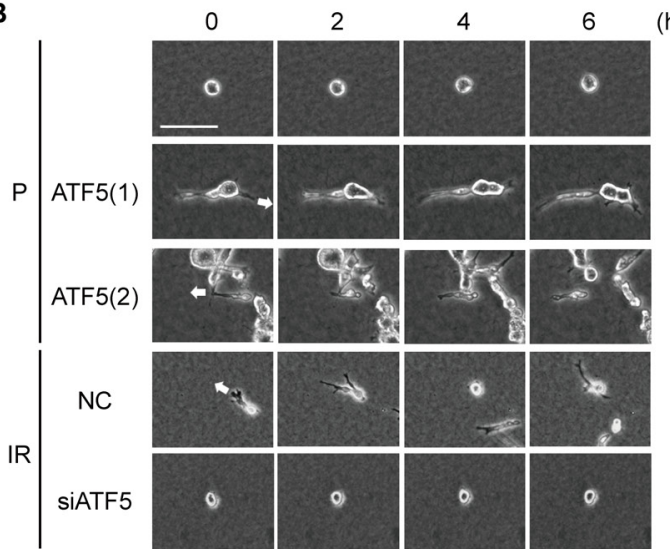

(h) $\mathbf{C}$

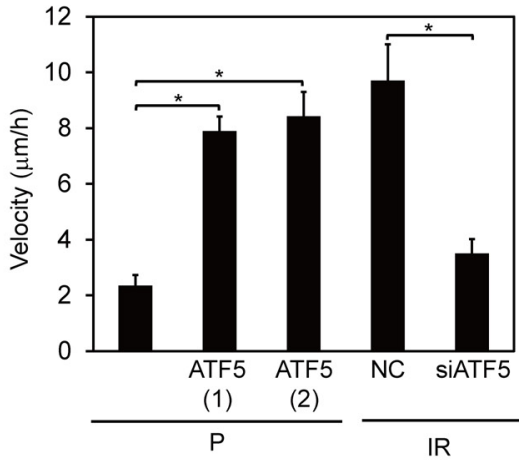

Figure 3: Invasiveness is dependent on ATF5 expression. (A) Western blot of ATF5 and GAPDH. The graph indicates the relative expression of ATF5. IR: subclonal A549 cells (P) that survived irradiation. NC: negative control cells. siATF5: cells transfected with siRNA targeting ATF5. Error bars = s.e.m. from 3 independent experiments. (B) Time-lapse phase-contrast images. The numbers indicate the time from the start of observation. The arrows indicate the direction of cell migration. P-ATF5(1), (2): subclonal P cells overexpressing ATF5. Bar $=100 \mu \mathrm{m}$. (C) Velocity of cell migration in B. Error bars = s.e.m. from 12 (P), 14 (P-ATF5(1) and (2)), or 15 (IR-NC and siATF5) cells in 3 independent experiments. $* P<0.05$. The cells were cultured in collagen gel-overlay conditions.

P-ATF5(1) cells, and AIIB2-treated P-ATF5(2) cells mainly exhibited round morphology, indicative of low invasiveness (Figure 4E, 4F and Supplementary Figure S1L, S1M). Collectively, these results indicate that ATF5 enhances invasiveness via integrin $\beta 1$.

\section{ATF5 represses MRLC diphosphorylation}

We previously reported that the invasiveness of IR cells is dependent on MRLC dephosphorylation and that diphosphorylated MRLC (PP-MRLC) suppresses invasiveness in IR cells [7]. Therefore, we investigated the role of ATF5 in the diphosphorylation of MRLC. PP-MRLC was expressed at higher levels in IR cells in which ATF5 was downregulated than in control IR cells (Figure 5A, 5B). Total myosin regulatory light chain (total-MRLC) expression was not significantly affected by ATF5 downregulation (Supplementary Figure S9A, S9B). Furthermore, P-ATF5(1) and (2) cells expressed lower level of PP-MRLC than did P cells; total-MLRC expression was not significantly different (Figure 5C, 5D). P-CAAX cells had similar levels of PP-MRLC and total-MRLC expression as P cells (Supplementary Figure S1N). These results indicate that ATF5 suppresses the diphosphorylation of MRLC. We then treated ATF5-suppressed IR cells with Y27632 reagent, which inhibits MRLC diphosphorylation $[27,28]$ (Supplementary Figure S10A, S10B) and investigated the role of MRLC diphosphorylation in invasiveness. Most ATF5-suppressed IR cells exhibited low invasiveness and round morphology, but Y27632 treatment induced an invasive phenotype in these cells (Figure 5E-5G and Video S5). Thus, ATF5 induces invasiveness via the dephosphorylation of MRLC in IR cells.

We examined whether integrin $\beta 1$ and MRLC regulate ATF5 and other proteins. Y27632 treatment did not affect ATF5 and integrin $\beta 1$ expression in $P$ cells (Supplementary Fig. S10A, B). In addition, AIIB2 treatment in IR cells did not affect ATF5 expression and MRLC diphosphorylation (Supplementary Figure S10C, S10D). These results suggest that integrin $\beta 1$ and PP-MRLC do not regulate the expression of ATF5 or each other.

\section{ATF5 expression is correlated with poor prognosis}

We next investigated the relationship between the expression of ATF5 and the prognosis of lung cancer patients. Kaplan-Meier curves of overall survival and first progression in non-small-cell lung cancers were generated by in silico meta-analysis to reveal a positive correlation between ATF5 expression and poor prognosis in non-small-cell lung cancer and lung adenocarcinoma (Figure 6A, 6B, 6C, 6D). In contrast, ATF5 expression was negatively correlated with poor prognosis of lung squamous cell carcinoma (Figure 6E, 6F). These results suggest that high expression of ATF5 is a high risk factor for the progression of non-small-cell lung cancer including lung adenocarcinoma.

\section{DISCUSSION}

In this study, we showed that ATF5 promotes radioresistance and malignancy in cancer cells (Figure 7). Furthermore, we showed that ATF5 expression was dependent on the cell cycle phase. In G2-M phases, cancer cells are radiosensitive because they express low levels of ATF5. In contrast, in G1-S phases, the cells are radioresistant because ATF5 expression induces cell cycle progression. In A549 cells, irradiation induces senescence and thereby leads to cell death [29]. In addition, cell 
A

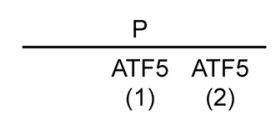

$(1)$
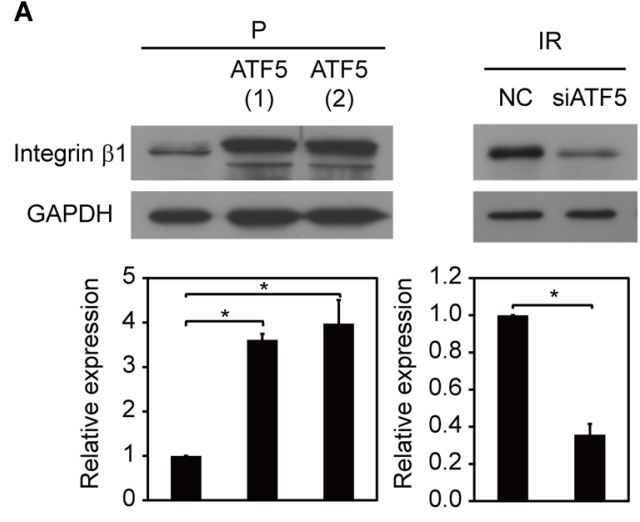

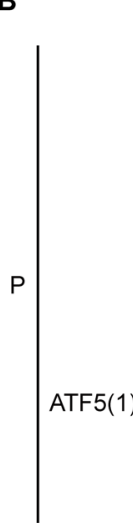

Integrin $\beta 1$
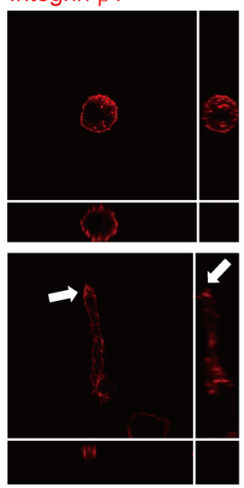

Merge
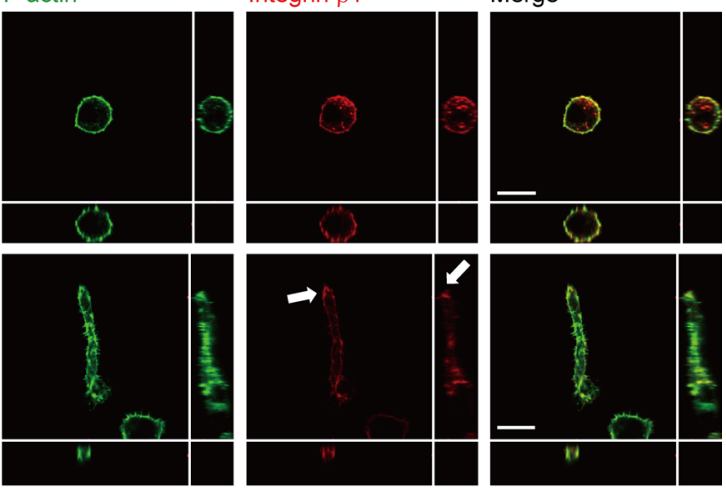

C

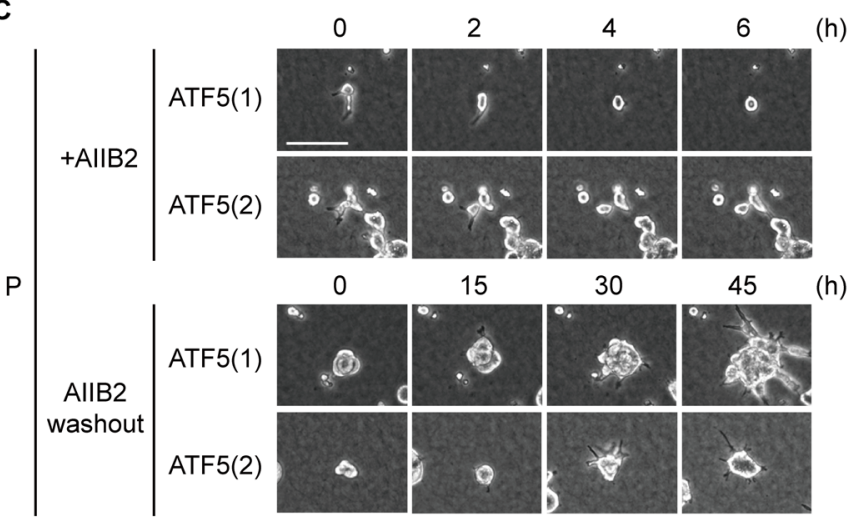

(h)

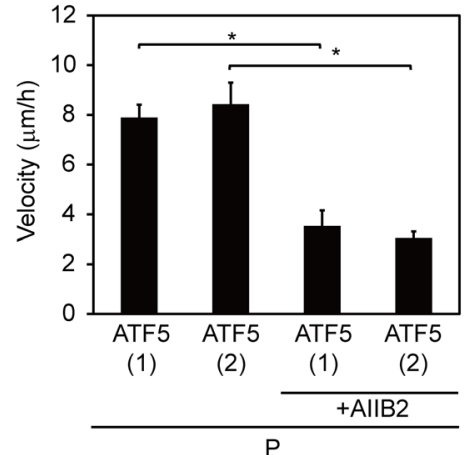

E

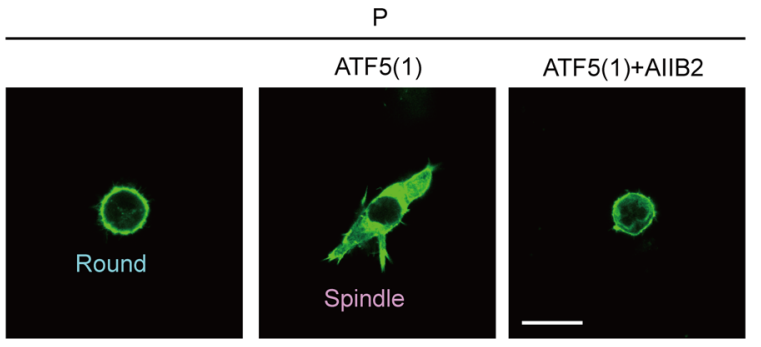

$\mathbf{F}$

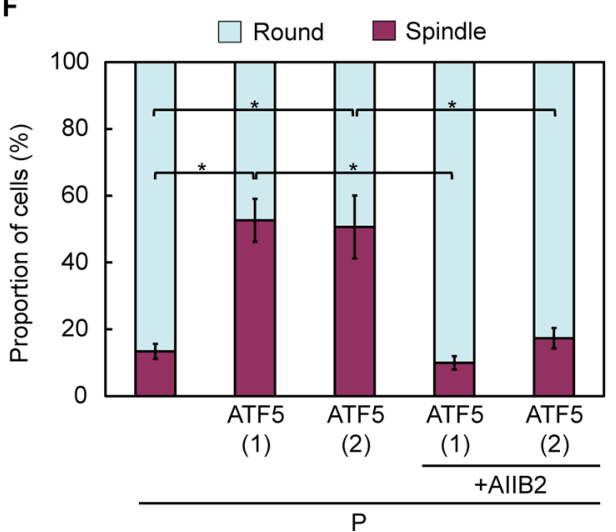

Figure 4: ATF5 induces integrin $\beta 1$ expression, promoting invasiveness. (A) Western blot of integrin $\beta 1$ and GAPDH. The graph indicates the relative expression of integrin $\beta 1$. P: subclonal A549 cells. P-ATF5(1), (2): subclonal P cells overexpressing ATF5. IR: P cells that survived irradiation. NC: negative control cells. siATF5: cells transfected with siRNA targeting ATF5. (B) Fluorescence images of F-actin and integrin $\beta 1$. Cross-sectional views are shown. The arrows show the accumulation of integrin $\beta 1$ at the tip of a protrusion. Bar $=$ $20 \mu \mathrm{m}$. (C) Time-lapse phase-contrast images. The numbers indicate the time after the addition of AIIB2 or washout of AIIB2. +AIIB2: cells with AIIB2. AIIB2 washout: cells after washout of AIIB2. Bar $=100 \mu \mathrm{m}$. (D) Velocity of cell migration in C. Error bars $=$ s.e.m. from 14 (P-ATF5(1) and (2)), 12 (P-ATF5(1)+AIIB2), or 15 (P-ATF5(2)+AIIB2) cells in 3 independent experiments. (E) Fluorescence images of F-actin. Round and spindle morphologies are displayed. Bar $=30 \mu \mathrm{m}$. (F) Proportion of cells in E. $* P<0.05$. Error bars $=$ s.e.m. from 3 independent experiments except $\mathrm{D}$. The cells were cultured in collagen gel-overlay conditions.

cycle arrest induces senescence [30]. Therefore, ATF5 may enhance radioresistance by promoting cell cycle progression after irradiation and thereby preventing cell senescence. Furthermore, ATF5 perturbs the activity of p53 [16], which enhances senescence [30]. Thus, ATF5 may also perturb cell senescence by repressing p53 activity, resulting in enhanced radioresistance. We also showed that A549 cells that survive irradiation express high levels of ATF5, which enhances malignant phenotypes such as tumorigenesis, growth, and invasiveness in cancer cells. In addition, ATF5 promotes the expression of integrin $\beta 1$ and represses MRLC diphosphorylation, thereby 
A

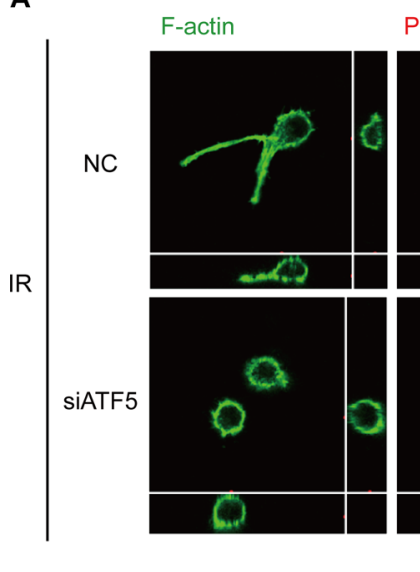

C

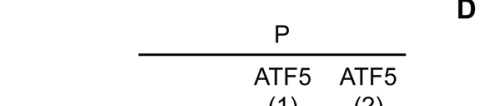

PP-MRLC

Total-MRLC

GAPDH

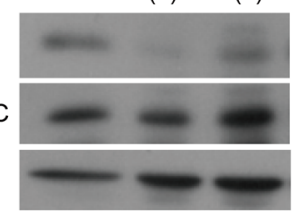

E

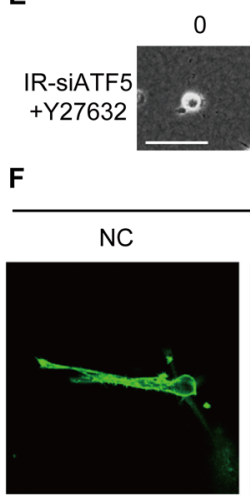

PP-MRLC

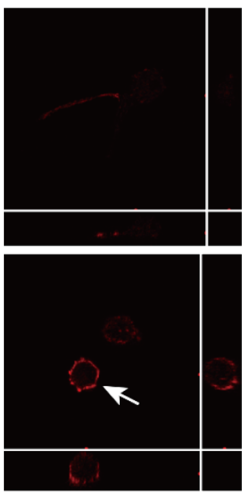

D
Merge

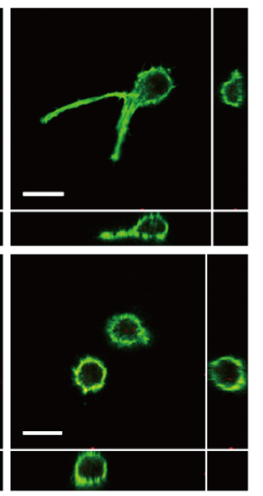

- Total-MRLC

$\square$ PP-MRLC
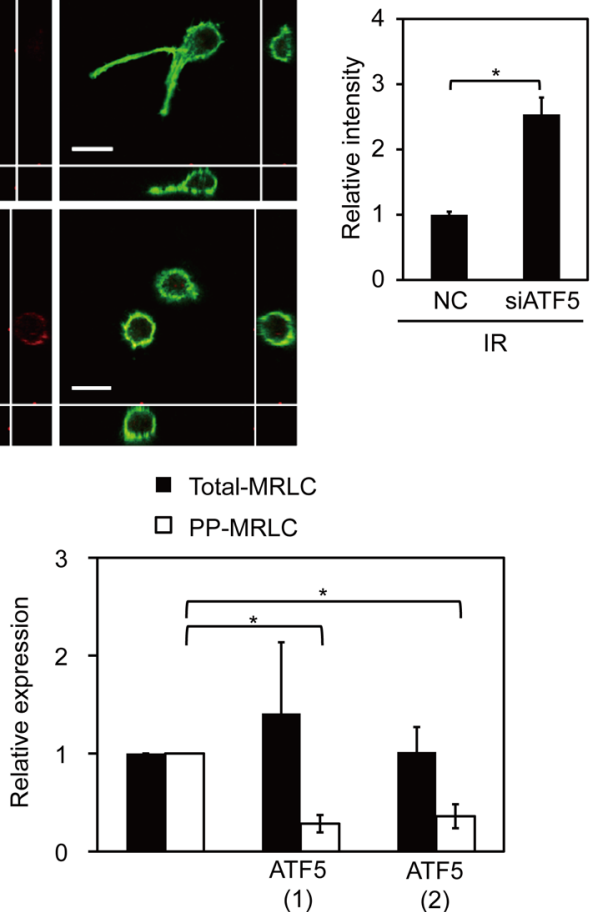

(h)

$\mathrm{P}$

G

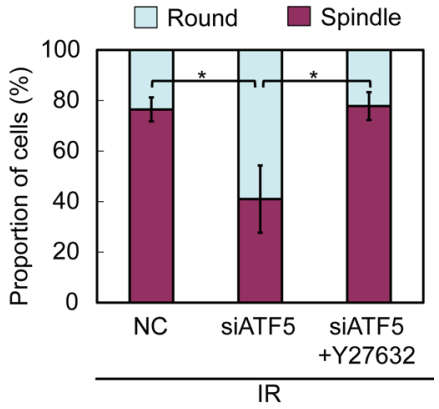

Figure 5: ATF5 perturbs the diphosphorylation of myosin regulatory light chain (MRLC), impairing invasiveness. (A) Fluorescence images of F-actin and diphosphorylated MRLC (PP-MRLC). Cross-sectional views are shown. Arrow shows the accumulation of PP-MRLC.IR: subclonal A549 cells (P) that survived irradiation. NC: negative control cells. siATF5: cells transfected with siRNA targeting ATF5. Bar $=20 \mu \mathrm{m}$. (B) Relative intensity of PP-MRLC in A. Error bars = s.e.m. from 40 cells in 3 independent experiments. (C) Western blot of PP-MRLC, total-MRLC, and GAPDH in cells on a dish. P-ATF5(1), (2): subclonal P cells overexpressing ATF5. (D) Relative expression of proteins in C. Error bars = s.e.m. from 3 independent experiments. (E) Time-lapse phase-contrast images. The numbers indicate the time after the addition of Y27632. +Y27632: cells treated with Y27632. Bar $=100 \mu$ m. (F) Fluorescence images of F-actin. Bar $=30 \mu \mathrm{m}$. (G) Proportion of cells in F categorized as round or spindle shape. Error bars = s.e.m. from 4 (IR-NC and siATF5) or 3 (IR-siATF5+Y27632) independent experiments. $* P<0.05$. The cells were cultured in collagen gel-overlay conditions except $\mathrm{C}$.

increasing invasiveness in cancer cells. A previous study showed that integrin $\beta 1$ regulates cell-matrix adhesion [25]. Furthermore, diphosphorylated MRLC induces high cellular contractile force generated by actomyosin [31]. Thus, ATF5 might regulate invasiveness via cellmatrix adhesion regulated by integrin $\beta 1$ and cellular contractile force modulated by MLRC phosphorylation. It has been unclear whether specific molecules regulate both radioresistance and malignant phenotypes, such as high proliferative ability and invasiveness, in cancer cells. In this study, we demonstrated that ATF5 enhances both radioresistance and malignancy in cancer cells after irradiation.

We showed that ATF5 perturbs MRLC phosphorylation in cancer cells. However, the detailed mechanisms of regulation in MRLC phosphorylation by ATF5 have not been identified. The possible mediators are Rho family proteins and specific kinases. RhoA, a Rho family protein, 


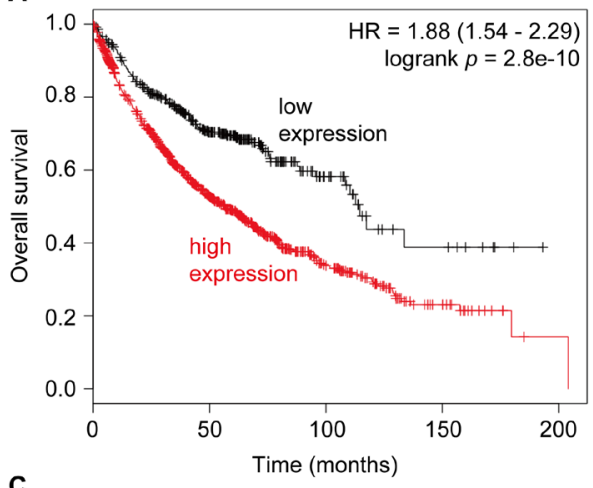

C

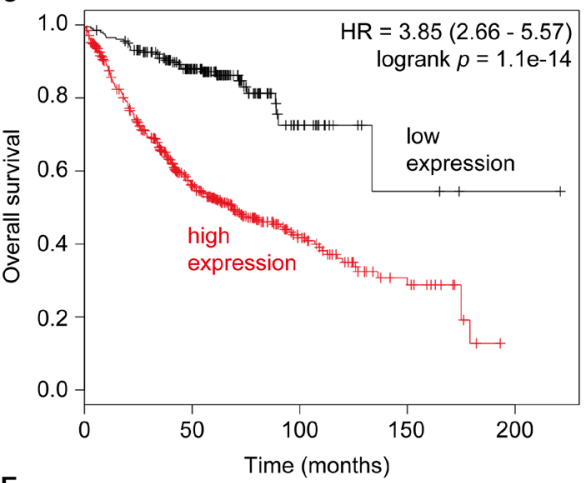

E

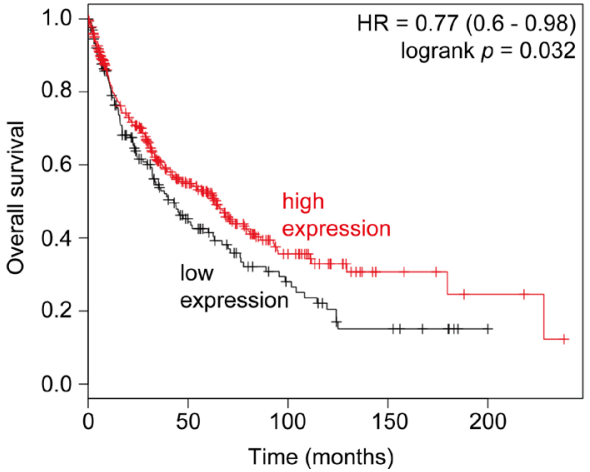

B

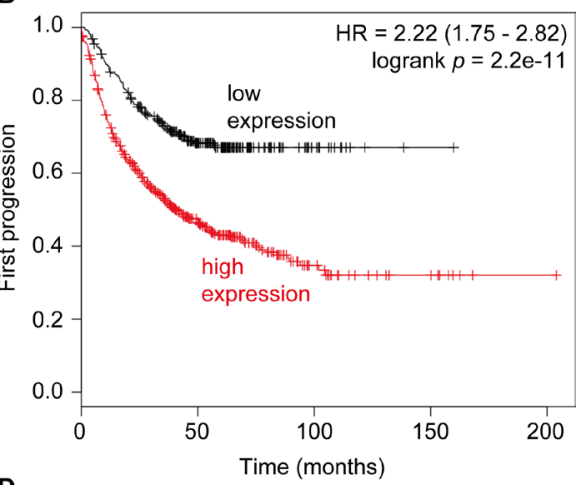

D

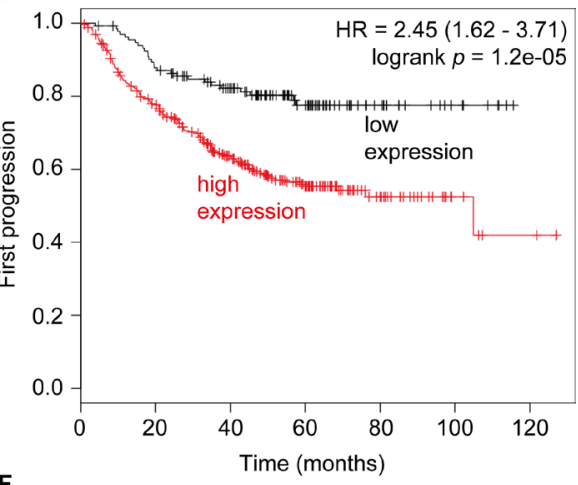

$\mathbf{F}$

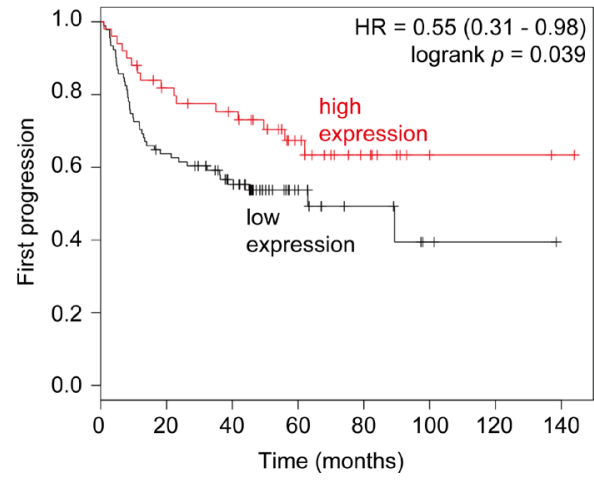

Figure 6: High expression of ATF5 is correlated with poor prognosis of lung cancer. Kaplan-Meier survival curves showing the probability of overall survival $(\mathbf{A}, \mathbf{C}, \mathbf{E})$ and first progression $(\mathbf{B}, \mathbf{D}, \mathbf{F})$ in relation to the expression of ATF5 lung cancer patients. A, B: the data of overall non-small-cell lung cancer. $\mathrm{C}, \mathrm{D}$ : the data of lung adenocarcinoma. $\mathrm{E}, \mathrm{F}$ : the data of lung squamous cell carcinoma. $n=$ 1432 (A), 787 (B), 719 (C), 461 (D), $525(\mathrm{E})$, or 141 (F) patients.

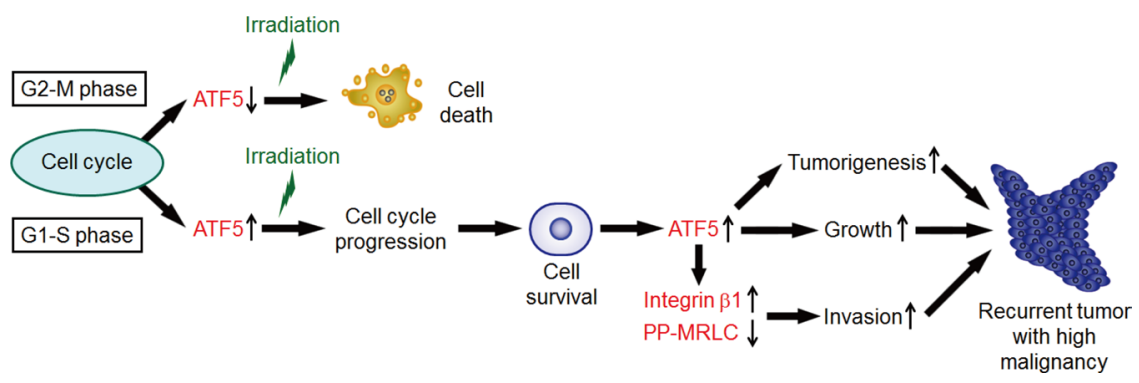

Figure 7: A model of tumor recurrence with high malignancy after irradiation. In G1-S phase, cancer cells express ATF5, which enhances radioresistance by promoting cell cycle progression. On the other hand, in G2-M phase, cancer cells express low levels of ATF5 and display radiosensitivity. Cells that survived after irradiation express high levels of ATF5. ATF5 promotes tumorigenesis and cell growth. ATF5 also induces invasiveness via integrin $\beta 1$ expression and inhibition of myosin regulatory light chain diphosphorylation (PP-MRLC). 
regulates MRLC phosphorylation by controlling Rho kinase (ROCK) activation $[32,28]$. Furthermore, myosin light chain kinase (MLCK) phosphorylates MRLC by $\mathrm{Ca}^{2+}$ stimulation [33]. Thus, ATF5 might be regulating MRLC phosphorylation via RhoA-ROCK signaling and/or MLCK functions.

In this study, we showed that ATF5 enhances both radioresistance and malignant phenotypes in cancer cells. This double ability of ATF5 embodies the concept of "oncogenic resistance" [34, 35, 36]. According to this concept, some molecules not only enable cancer cells to resist some therapies, such as chemotherapy and radiotherapy, but also drive cancer progression. For example, BCL-ABL, Akt, and BCL-X enhance the resistance to paclitaxel, a commonly used chemotherapeutic reagent. These molecules also drive tumorigenesis [34]. We illustrated the concept in this study by showing that ATF5 induces both radioresistance and malignancy in cancer cells. We suggest that ATF5 functions as one of the key molecules in oncogenic resistance to radiotherapy.

We suggest that ATF5 is a possible therapeutic target for the treatment of malignant tumors in combination with radiotherapy. We demonstrated that ATF5 expression is correlated with poor prognosis of lung cancer. Furthermore, previous studies have indicated that repression of ATF5 induces cancer cell death and that ATF5 inhibition does not affect the viability of non-cancerous neural and breast cells $[14,15]$. In addition, ATF5 induction in glioma cells enhances drug resistance [37]. These results support the idea that ATF5 is a possible therapeutic target for cancer treatment. From the results in this study, we suggest that ATF5 is a key regulator of cancer recurrence correlated with poor prognosis after radiotherapy. Therefore, inhibition of ATF5 may be an effective way to enhance radiosensitivity in cancer cells and prevent the recurrence and progression of cancer after radiotherapy.

\section{MATERIALS AND METHODS}

\section{Cell culture and gene manipulation}

The A549 human lung adenocarcinoma cell line was purchased from American Type Culture Collection (Manassas, VA). Subclonal A549 cells (P cells) and irradiation-tolerant $\mathrm{P}$ cells (IR cells) were established as previously reported [6]. P cells overexpressing the ATF5 gene were obtained by transfecting cells with a pCMV6-XL5 vector carrying a human cDNA clone of ATF5 (OriGene, Rockville, MD) using Attractene Transfection Reagent (Qiagen, Hilden, Germany). P-ATF5(1) and (2) cells were established by subcloning $\mathrm{P}$ cells that overexpressed the ATF5 gene. P cells were transfected with a phmAG1-H-Ras-CAAX vector [38] using Attractene Transfection Reagent and subcloned for the establishment of P-CAAX cells. For transient overexpression of the genes, we used Lipofectamine 2000 reagent (Invitrogen, Carlsbad, CA). The cells were cultured in Dulbecco's modified Eagle medium (DMEM; Sigma, St Louis, MO) containing 10\% fetal bovine serum (Equitech-Bio Inc., Kerrville, TX or Biowest, Nuaillé, France) and 1\% antibiotic/antimycotic solution (Sigma). The cells were incubated at $37^{\circ} \mathrm{C}$ in a humidified incubator with $5 \% \mathrm{CO}_{2}$. siRNA and random RNA (for negative control) duplexes were synthesized using an in vitro transcription $\mathrm{T} 7 \mathrm{kit}$ (Takara, Otsu, Japan). The target sequences for the downregulation of specific genes were as follows: 5'-CAAAAATAAAACGAAACATTT-3' for ATF5, 5'-CAAAGTTTGAAGAAATATACC-3' for cyclin A2, and 5'-CAAGGAAAAGACATACTTAAG-3' for cyclin E1 (sense sequence). The siRNA or random RNA duplexes were transfected into the cells using Lipofectamine RNAiMAX Reagent (Invitrogen). The cells transfected with siRNA or random RNA were used in experiments 3 days after transfection. A type I collagen gel (1.6 mg/mL, Cell matrix I-P; Nitta Gelatin, Osaka, Japan) was used for collagen gel-overlay culture and culture on collagen gels. The VenorGeM Mycoplasma Detection Kit (Minerva Biolabs, Berlin, Germany) was used to confirm the absence of mycoplasma contamination in all cells.

\section{Antibodies and reagents}

Anti-ATF5 (1:7500-1:40,000; N-17, cat. \#sc-46935; Santa Cruz Biotechnology, Inc., Santa Cruz, CA), anticyclin A2 (1:5000; cat. \#4656; Cell Signaling Technology, Danvers, MA), anti-cyclin B1 (1:3000; cat. \#4138; Cell Signaling Technology), anti-cyclin D1 (1:1000; cat. \#2978; Cell Signaling Technology), anti-cyclin D3 (1:30,000; cat. \#2936; Cell Signaling Technology), anti-cyclin E1 (1:60,000; cat. \#4129; Cell Signaling Technology), anti-phistone (1:2000; cat. \#3377; Cell Signaling Technology), anti-integrin $\beta 1$ (1:1000; cat. \#610467; BD Bioscience, San Jose, CA), anti-GAPDH (1:10,000,000; cat. \#1103016; Ambion, Foster City, CA), anti-diphosphorylated-myosin regulatory light chain (PP-MRLC; 1:100-1:300; cat. \#3674; Cell Signaling Technology), anti-total-myosin regulatory light chain (total-MRLC; 1:100; cat. \#3672; Cell Signaling Technology), HRP anti-goat IgG (1:20,000; cat. \#305-035003; Jackson ImmunoResearch Laboratories, Inc., West Grove, PA), HRP anti-rabbit IgG (1:10,000; cat. \#7074; Cell Signaling Technology), and HRP anti-mouse IgG (1:10,000-1:200,000; cat. \#70-6516; Bio-Rad, Hercules, CA) were used for western blotting. MFP488-phalloidin (1:500-1:1000; Mo Bi Tee, Göttingen, Germany) or Alexa Fluor 555-phalloidin (1:500; cat. \#8953; Cell Signaling Technology) was used for F-actin staining. Anti-integrin $\beta 1$ AIIB2 (350 ng/mL; Developmental Studies Hybridoma Bank at the University of Iowa, Iowa City, IA), anti-PPMRLC (1:150), anti-total-MRLC (1:150), Alexa Fluor 594 anti-rat IgG (1:500; cat. \#A-11007; Invitrogen), and Alexa Fluor 594 anti-rabbit IgG (1:500; cat. \#A-11012; 
Invitrogen) were used for immunofluorescence staining. Propidium iodide (Sigma) was used for flow cytometry. Incubation with nocodazole $(0.04 \mu \mathrm{g} / \mathrm{mL}$; Sigma $)$ for $12 \mathrm{~h}$ was used to synchronize cells at $\mathrm{M}$ phase. Incubation with mimosine (500 $\mu \mathrm{M}$; Sigma) for $24 \mathrm{~h}$ was used to inhibit the $\mathrm{G} 1 / \mathrm{S}$ cell cycle transition. Incubation with staurosporine (2 $\mu \mathrm{M}$; Enzo Life Sciences, Plymouth Meeting, PA) for $4 \mathrm{~h}$ was used to induce apoptosis. Anti-integrin $\beta 1$ AIIB2 (300 $\mathrm{ng} / \mathrm{mL}$ ) was used to inhibit integrin $\beta 1$ activity. Y27632 (20 $\mu \mathrm{M}$, Sigma) was used to inhibit MRLC diphosphorylation.

\section{Western blotting}

To detect proteins from cells cultured on a dish, $0.5 \times$ $10^{5}$ or $1.0 \times 10^{5}$ cells were seeded on a culture dish (radius of $17.5 \mathrm{~mm}$ ). One or two days after seeding, cell lysates were prepared using an improved method as previously reported [39]. To detect proteins from cells cultured in collagen geloverlay conditions, $5 \times 10^{4}$ cells were seeded on a culture dish (radius of $17.5 \mathrm{~mm}$ ) filled with $500 \mu \mathrm{L}$ of collagen gel. One day after seeding, $250 \mu \mathrm{L}$ of collagen sol solution was poured on the cells and incubated for approximately $30 \mathrm{~min}$ at $37^{\circ} \mathrm{C}$ to induce gelation. The dish was then filled with culture medium and incubated at $37^{\circ} \mathrm{C}$. After 1 day, cell lysates were prepared using an improved method as previously described [39]. Western blotting and quantification of protein expression were performed as previously reported [39, 40], but with blocking for $2 \mathrm{~h}$ to detect ATF5.

\section{Colony formation assay}

Initially, $3.5 \times 10^{5}$ cells (for non-treated P-3, P-ATF5(1), and P-ATF5 (2) cells), $1.3 \times 10^{5}$ cells (for cells synchronized with nocodazole treatment), $2.6 \times 10^{5}$ cells (for cells treated with mimosine and respective control cells), or $2.5 \times 10^{5}$ cells (for cells transfected with siRNA or random RNA) were seeded in a $12.5-\mathrm{cm}^{2}$ cell culture flask. Two days after seeding, cells were irradiated or non-irradiated at room temperature with a dose of $10 \mathrm{~Gy}$. Cell cycles were synchronized with nocodazole treatment. Immediately after irradiation, the irradiated cells were dispersed with trypsin-EDTA. For mimosine-treated cells and the respective control cells, mimosine was added to the flask during the last minute of irradiation, and the cells were dispersed with trypsin-EDTA $24 \mathrm{~h}$ after irradiation. After dispersion, $1.0 \times 10^{3}$ cells (for non-treated P-3, P-ATF5(1), and P-ATF5(2) cells), $5.0 \times 10^{3}$ cells (for cells synchronized with nocodazole treatment), or $1.0 \times 10^{4}$ cells (for cells treated with mimosine and the respective control cells) were reseeded on a 24-well plate. At the same time, non-irradiated cells were dispersed, and 100 cells were re-seeded on a culture dish (radius of $17.5 \mathrm{~mm}$ ). The number of lump colonies of irradiated cells in a well and non-irradiated cells in a dish were counted 12 or 16 days after irradiation using a phase-contrast microscope (TE300; Nikon Instech Co., Tokyo, Japan; CKX41; Olympus, Tokyo, Japan) with a $4 \times$ objective.

\section{Flow cytometry}

Cells $\left(2 \times 10^{5}\right)$ were seeded on a culture dish (radius of $17.5 \mathrm{~mm}$ ). Two days after seeding, the cells were dispersed with trypsin-EDTA. The cells were washed with phosphatebuffered saline (PBS) and fixed with 70\% iced ethanol with PBS for $30 \mathrm{~min}$ or more on ice. After fixation, the cells were incubated with $50 \mu \mathrm{g} / \mathrm{mL}$ propidium iodide and $50 \mu \mathrm{g} / \mathrm{mL}$ RNase A (Macherey-Nagel, Düren, Germany) in PBS for $30 \mathrm{~min}$ at $37^{\circ} \mathrm{C}$. After incubation, the cell cycle phase was detected using a FACSCalibur cell analyzer (BD Biosciences).

\section{Cell growth assay}

Cells $\left(5 \times 10^{4}\right)$ were seeded on a culture dish (radius of $17.5 \mathrm{~mm}$ ) filled with $500 \mu \mathrm{L}$ of collagen gel. One day after seeding, $250 \mu \mathrm{L}$ of collagen sol solution was poured on the cells and incubated for approximately $30 \mathrm{~min}$ at $37^{\circ} \mathrm{C}$ to induce gelation. The dish was then filled with culture medium and incubated at $37^{\circ} \mathrm{C}$. After 1 day, cells were randomly imaged under a phase-contrast microscope (TE300; Nikon Instech Co.) with a 10× objective, and the colony size was determined by calculating the area of the colonies using ImageJ software (National Institutes of Health, Bethesda, MD). After 1, 2, or 3 day(s), the cells were treated with $0.1 \%$ collagenase-L (Nitta Gelatin) in PBS and incubated for $1 \mathrm{~h}$ at $37^{\circ} \mathrm{C}$. After incubation, the cells were collected and suspended in $500 \mu \mathrm{L}$ of trypsinEDTA. The OD600 was calculated using an absorption spectrometer (SmartSpec Plus; Bio-Rad), and the cell number was determined according to the following formula: cell number $=\mathrm{OD} 600 \times 6.85 \times 10^{5}$. Alternatively, cell number was directly counted by a counting chamber.

\section{Time-lapse imaging}

A glass dish (radius of $12.5 \mathrm{~mm}$ ) was filled with $500 \mu \mathrm{L}$ of collagen gel, and $1.0 \times 10^{4}$ cells were seeded on the gel. After $24 \mathrm{~h}, 250 \mu \mathrm{L}$ of collagen sol solution was poured on the cell and incubated for approximately 30 min at $37^{\circ} \mathrm{C}$ to induce gelation. The dish was then filled with culture medium and incubated at $37^{\circ} \mathrm{C}$. After 1 day, the dish was filled with medium and sealed with silicone grease to prevent changes in the $\mathrm{pH}$ of the medium. A phase-contrast microscope (TE300 or TS100; Nikon Instech Co.) with a $10 \times$ objective was used for time-lapse imaging. The dish with the cells was kept at $37^{\circ} \mathrm{C}$ in an acrylic resin box or on a thermo plate. Image-Pro software (Media Cybernetics Inc., Silver Spring, MD) or WraySpect software (Wraymer Inc., Osaka, Japan) was used to capture images every $5 \mathrm{~min}$ for time-lapse imaging. AIIB2 or Y27632 was added to the samples $24 \mathrm{~h}$ after the start of observation, and the observation was continued. After 24 $\mathrm{h}$, the samples were washed with PBS, and the observation was continued. The velocity of cell migration was calculated by measuring the displacement of the cell center every $1 \mathrm{~h}$ using ImageJ software. The cells were selected randomly. 


\section{Immunofluorescence staining}

Cells $\left(4 \times 10^{3}\right)$ were seeded on a glass dish (radius of $8.0 \mathrm{~mm}$ ) filled with $100 \mu \mathrm{L}$ of collagen gel. One day after seeding, $50 \mu \mathrm{L}$ of collagen sol solution was poured on the cells and incubated for approximately $30 \mathrm{~min}$ at $37^{\circ} \mathrm{C}$ to induce gelation. The dish was then filled with culture medium and incubated at $37^{\circ} \mathrm{C}$. After 1 day, cells were fixed with $4 \%$ formaldehyde in PBS and permeabilized with $0.5 \%$ Triton X-100 in PBS. Cells were blocked with $0.5 \%$ bovine serum albumin (for integrin $\beta 1$ staining) or $0.5 \%$ skim milk (for PP-MRLC and total-MRLC staining) in PBS. Integrin $\beta 1$, PP-MRLC, total-MRLC, and F-actin were stained with antibodies or a reagent, as described above. Fluorescence images were obtained using a confocal laser scanning microscope ( $\mathrm{C} 1$ confocal imaging system; Nikon Instech Co.) with a $60 \times$ objective. The fluorescence intensities were analyzed using Image-Pro software (Media Cybernetics Inc.).

\section{qPCR}

Cells $\left(5 \times 10^{4}\right)$ were seeded on a culture dish (radius of $17.5 \mathrm{~mm}$ ) filled with $500 \mu \mathrm{L}$ of collagen gel. 1 day after seeding, $250 \mu \mathrm{L}$ of collagen sol solution was poured on the cells and incubated for approximately $30 \mathrm{~min}$ at $37^{\circ} \mathrm{C}$ to induce gelation. The dish was then filled with culture medium and incubated at $37^{\circ} \mathrm{C}$. After 1 day, cells were lysed with TriPure Isolation Reagent (Roche, Basel, Switzerland) for RNA extraction. Reverse transcription reaction was performed using ReverTra Ace qPCR RT Master Mix (TOYOBO, Osaka, Japan). qPCR was performed with DyNAmo ColorFlash SYBR Green qPCR Kit (Thermo Fisher Scientific Inc., Waltham, MA). Primers were as follows: $\beta$-actin (for internal control), 5'-GAGCCTCGCCTTTGCCGATCC-3' (upper) and 5'-ACATGCCGGAGCCGTTGTCG-3' (lower); and integrin $\beta 1,5^{\prime}$-GACGCCGCGCGGAAAAGATG-3' (upper) and 5'-GCACCACCCACAATTTGGCCC-3' (lower).

\section{Roundness index analysis}

Cells $\left(1 \times 10^{4}\right)$ were seeded on a glass dish (radius of $12.5 \mathrm{~mm}$ ) filled with $250 \mu \mathrm{L}$ of collagen gel. One day after seeding, $125 \mu \mathrm{L}$ of collagen sol solution was poured on the cells and incubated for approximately $30 \mathrm{~min}$ at $37^{\circ} \mathrm{C}$ to induce gelation. The dish was then filled with culture medium and incubated at $37^{\circ} \mathrm{C}$ with or without reagents. After 1 day, cells were fixed with $4 \%$ formaldehyde in PBS and permeabilized with $0.5 \%$ Triton X-100 in PBS. F-actin was stained with MFP488 phalloidin, as described above. Fluorescence images were obtained using a confocal laser scanning microscope ( $\mathrm{C} 1$ confocal imaging system; Nikon Instech Co.) with a $60 \times$ objective. The proportion of cells with round or spindle morphology was determined using the roundness index analysis, as previously reported [6].

\section{Luciferase reporter assay}

A 24-well plate was filled with $100 \mu \mathrm{L}$ of collagen gel, and $4.0 \times 10^{4}$ cells were seeded on the gel. After 2 days, luciferase plasmids ( $300 \mathrm{ng} / \mathrm{mL}$ pCRE-Luc, $30 \mathrm{ng} /$ $\mathrm{mL}$ pRL-TK, $1200 \mathrm{ng} / \mathrm{mL}$ pcDNA3) were transfected using Lipofectamine 2000 (Invitrogen). The cells were cultured in medium without antibiotics supplemented with $10 \%$ fetal bovine serum. After 1 day, the luciferase activities were detected using the Dual Luciferase Reporter Assay System (Promega, Madison, WI).

\section{Apoptosis assay}

Cells $\left(8 \times 10^{2}\right)$ were seeded on a glass dish (radius of $2.5 \mathrm{~mm}$ ) filled with $25 \mu \mathrm{L}$ of collagen gel. One day after seeding, $15 \mu \mathrm{L}$ of collagen sol solution was poured on the cells and incubated for approximately $30 \mathrm{~min}$ at $37^{\circ} \mathrm{C}$ to induce gelation. The dish was then filled with culture medium and incubated at $37^{\circ} \mathrm{C}$. After 1 day, apoptotic cells were detected using the GFP-Certified Apoptosis/ Necrosis Detection System (Enzo Life Sciences).

\section{Experiments in mice}

PBS-suspended cells $\left(2.5 \times 10^{6}\right)$ were injected subcutaneously into the dorsal side of 7-week-old male BALB/cSlc-nu/nu mice (Japan SLC, Inc., Hamamatsu, Japan; 10 animals each). Macroscopic observation and tumor volume measurements were performed twice a week. The tumor volume was determined according to the following formula: tumor volume $\left(\mathrm{mm}^{3}\right)=$ length $(\mathrm{mm}) \times(\text { width }(\mathrm{mm}))^{2} / 2$. All animals were sacrificed 47 days after injection, and the tumor masses were dissected. Tumor tissues were fixed with 3.7\% formaldehyde and embedded in paraffin. For each sample, $4 \mu \mathrm{m}$-thick sections were stained with hematoxylin and eosin. Mitotic cells were counted in 9 or 10 random highpower fields, and the average number of mitotic cells was determined. The animal experiments were strictly compliant with the animal care guidelines of Hokkaido University.

\section{Data analysis of patients}

Kaplan-Meier curves were obtained by using the Kaplan-Meier plotter [41] at http://kmplot.com/analysis/. This software contains the databases of Cancer Biomedical Informatics Grid, Gene Expression Omnibus, and The Cancer Genome Atlas [41]. We used the "Auto select best cutoff" function, which computes the best performing threshold to determine high or low expression of ATF5.

\section{Statistics}

The statistical significance of the experimental data was analyzed as follows. First, we determined whether the data met the normal distribution using the Kolmogorov-Smirnov test $(P>0.05$ indicated the data 
met the normal distribution). When we analyzed the data set with normal distributions, we determined whether the variance of two data sets was significantly different $(P<0.05$ indicated the variance was significantly different) using the $F$-test. For data sets with significantly different variances, we used Welch's $t$-test to determine the significance ( $P$-value). On the other hand, for data sets without statistically different variances, we used Student's $t$-test to determine the significance ( $P$-value). When we analyzed data sets with non-normal distributions, we determined the significance ( $P$-value) using the Mann-Whitney $U$-test. We used sufficient sample sizes to evaluate the statistical significance in each experiment (at least three samples each).

\section{ACKNOWLEDGMENTS}

The authors thank Takeomi Mizutani and Kazushige Kawabata for discussion; Utano Tomaru for assistance of experiments in mice; Sawa Kobayashi for technical assistance; Xue Li for the establishment of P-CAAX, P-ATF5(1), and (2) cells; Takeshi Nishioka, Ai Kohda, and Taishi Yamada for help in designing experiments; and Mayu Fukuda, Masahiro Maeda, Kentaro Minami, and Takashi Yamaga for help in data analysis.

\section{Grant support}

This study was supported by JSPS KAKENHI Grant Numbers 26430104 to H.H., 24390285 to H.H. and M.Y., 26860964 to S.I. This study was also partly supported by Special Expenditures for "Reverse Translational Research from Advanced Medical Technology to Advanced Life Science" to S.I., M.I., H.S., H.H. granted by MEXT, Japan.

\section{Disclosure of potential conflicts of interest}

The authors disclose no potential conflicts of interest.

\section{REFERENCES}

1. Ahmad SS, Duke S, Jena R, Williams MV, Burnet NG. Advances in radiotherapy. BMJ. 2012; 345:e7765.

2. von Essen CF. Radiation enhancement of metastasis: a review. Clin Exp Metastasis. 1991; 9:77-104.

3. Wild-Bode C, Weller M, Rimner A, Dichgans J, Wick W. Sublethal irradiation promotes migration and invasiveness of glioma cells: implications for radiotherapy of human glioblastoma. Cancer Res. 2001; 61:2744-50.

4. Tsutsumi K, Tsuda M, Yazawa N, Nakamura H, Ishihara S, Haga H, Yasuda M, Yamazaki R, Shirato H, Kawaguchi H, Nishioka T, Ohba Y. Increased motility and invasiveness in tumor cells that survive 10 Gy irradiation. Cell Struct Funct. 2009; 34:89-96.
5. Nishioka T, Yasuda M, Takeshima T, Haga H, Miyai Y, Shibata K, Yamazaki R, Shirato H, Teduka M, Date H. Radiation-induced cancer cell repopulation: a possible mechanism implied by experiments using transplantable mouse-derived sarcoma cell line. Cell Struct Funct. 2011; 36:13-20.

6. Ishihara S, Haga H, Yasuda M, Mizutani T, Kawabata K, Shirato H, Nishioka T. Integrin beta1-dependent invasive migration of irradiation-tolerant human lung adenocarcinoma cells in $3 \mathrm{D}$ collagen matrix. Biochem Biophys Res Commun. 2010; 396:651-5.

7. Ishihara S, Yasuda M, Nishioka T, Mizutani T, Kawabata K, Shirato H, Haga H. Irradiation-tolerant lung cancer cells acquire invasive ability dependent on dephosphorylation of the myosin regulatory light chain. FEBS Lett. 2013; 587:732-736.

8. Li X, Ishihara S, Yasuda M, Nishioka T, Mizutani T, Ishikawa M, Kawabata K, Shirato H, Haga H. Lung cancer cells that survive ionizing radiation show increased integrin a2ß1- and EGFR-dependent invasiveness. PLoS One. 2013; 8:e70905.

9. Nishizawa M, Wakabayashi-Ito N, Nagata S. Molecular cloning of cDNA and a chromosomal gene encoding GPE1-BP, a nuclear protein which binds to granulocyte colony-stimulating factor promoter element 1. FEBS Lett. 1991; 282:95-7.

10. Pati D, Meistrich ML, Plon SE. Human Cdc34 and Rad6B ubiquitin-conjugating enzymes target repressors of cyclic AMP-induced transcription for proteolysis. Mol Cell Biol. 1999; 19:5001-13.

11. Persengiev SP, Green MR. The role of ATF/CREB family members in cell growth, survival and apoptosis. Apoptosis. 2003; 8:225-8.

12. Angelastro JM, Ignatova TN, Kukekov VG, Steindler DA, Stengren GB, Mendelsohn C, Greene LA. Regulated expression of ATF5 is required for the progression of neural progenitor cells to neurons. J Neurosci. 2003; 23:4590-600.

13. Leong DT, Abraham MC, Gupta A, Lim TC, Chew FT, Hutmacher DW. ATF5, a possible regulator of osteogenic differentiation in human adipose-derived stem cells. J Cell Biochem. 2012; 113:2744-53.

14. Angelastro JM, Canoll PD, Kuo J, Weicker M, Costa A, Bruce JN, Greene LA. Selective destruction of glioblastoma cells by interference with the activity or expression of ATF5. Oncogene. 2006; 25:907-16.

15. Monaco SE, Angelastro JM, Szabolcs M, Greene LA. The transcription factor ATF5 is widely expressed in carcinomas, and interference with its function selectively kills neoplastic, but not nontransformed, breast cell lines. Int J Cancer. 2007; 120:1883-90.

16. Nishioka T, Miyai Y, Haga H, Kawabata K, Shirato H, Homma A, Shibata K, Yasuda M. Novel function of transcription factor ATF5: blockade of p53-dependent apoptosis induced by ionizing irradiation. Cell Struct Funct. 2009; 34:17-22. 
17. Sinclair WK, Morton RA. Variations in X-ray response during the division cycle of partially synchronized chinese hamster cells in culture. Nature. 1963; 199:1158-60.

18. Terasima T, Tolmach LJ. Variations in several responses of HeLa cells to x-irradiation during the division cycle. Biophys J. 1963; 3:11-33

19. Biade S, Stobbe CC, Chapman JD. The intrinsic radiosensitivity of some human tumor cells throughout their cell cycles. Radiat Res. 1997; 147:416-21.

20. Cao R, Ding Q, Li P, Xue J, Zou Z, Huang J, Peng G. SHP1-mediated cell cycle redistribution inhibits radiosensitivity of non-small cell lung cancer. Radiat Oncol. 2013; 8:178.

21. Zieve GW, Turnbull D, Mullins JM, McIntosh JR. Production of large numbers of mitotic mammalian cells by use of the reversible microtubule inhibitor nocodazole. Nocodazole accumulated mitotic cells. Exp Cell Res. 1980; 126:397-405.

22. Schafer KA. The cell cycle: a review. Vet Pathol. 1998; 35:461-78.

23. Hendzel MJ, Wei Y, Mancini MA, Van Hooser A, Ranalli T, Brinkley BR, Bazett-Jones DP, Allis C. D.Mitosis-specific phosphorylation of histone $\mathrm{H} 3$ initiates primarily within pericentromeric heterochromatin during G2 and spreads in an ordered fashion coincident with mitotic chromosome condensation. Chromosoma. 1997; 106:348-60.

24. Lalande M. A reversible arrest point in the late G1 phase of the mammalian cell cycle. Exp Cell Res. 1990; 186:332-9.

25. Hynes RO. Integrins: bidirectional, allosteric signaling machines. Cell. 2002; 110:673-87.

26. Hall DE, Reichardt LF, Crowley E, Holley B, Moezzi H, Sonnenberg A, Damsky CH. The alpha 1/beta 1 and alpha 6/beta 1 integrin heterodimers mediate cell attachment to distinct sites on laminin. J Cell Biol. 1990; 110: 2175-84.

27. Hirose M, Ishizaki T, Watanabe N, Uehata M, Kranenburg O, Moolenaar WH, Matsumura F, Maekawa M, Bito H, Narumiya S. Molecular dissection of the Rho-associated protein kinase (p160ROCK)-regulated neurite remodeling in neuroblastoma N1E-115 cells. J Cell Biol. 1998; 141:1625-36.

28. Ueda K, Murata-Hori M, Tatsuka M, Hosoya H. Rhokinase contributes to diphosphorylation of myosin II regulatory light chain in nonmuscle cells. Oncogene. 2002; 21:5852-60.
29. Luo H, Yount C, Lang H, Yang A, Riemer EC, Lyons K, Vanek KN, Silvestri GA, Schulte BA, Wang GY. Activation of p53 with Nutlin-3a radiosensitizes lung cancer cells via enhancing radiation-induced premature senescence. Lung Cancer. 2013; 81:167-73.

30. van Deursen JM. The role of senescent cells in ageing. Nature. 2014; 509:439-46.

31. Mizutani T, Haga H, Koyama Y, Takahashi M, Kawabata K. Diphosphorylation of the myosin regulatory light chain enhances the tension acting on stress fibers in fibroblasts. J Cell Physiol. 2006; 209:726-31.

32. Ridley AJ. RhoA, RhoB and RhoC have different roles in cancer cell migration. J Microsc. 2013; 251:242-9.

33. Somlyo AP, Somlyo AV. Ca2+ sensitivity of smooth muscle and nonmuscle myosin II: modulated by $\mathrm{G}$ proteins, kinases, and myosin phosphatase. Physiol Rev. 2003; 83:1325-58.

34. Blagosklonny MV. Oncogenic resistance to growth-limiting conditions. Nat Rev Cancer. 2002; 2:221-5.

35. Blagosklonny MV. Antiangiogenic therapy and tumor progression. Cancer Cell. 2004; 5:13-7.

36. Blagosklonny MV. Why therapeutic response may not prolong the life of a cancer patient: selection for oncogenic resistance. Cell Cycle. 2005; 4:1693-8.

37. Sheng Z, Li L, Zhu LJ, Smith TW, Demers A, Ross AH, Moser RP, Green MR. A genome-wide RNA interference screen reveals an essential CREB3L2-ATF5-MCL1 survival pathway in malignant glioma with therapeutic implications. Nat Med. 2010; 16:671-7.

38. Ishida S, Tanaka R, Yamaguchi N, Ogata G, Mizutani T, Kawabata K, Haga H. Epithelial sheet folding induces lumen formation by Madin-Darby canine kidney cells in a collagen gel. PLoS One. 2014; 9:e99655.

39. Ishihara S, Mizutani T, Kawabata K, Haga H. An improved method for western blotting when extracting proteins from mammalian cells cultured on a collagen gel under serumfree conditions. Cytotechnology. 2014; doi 10.1007/ s10616-014-9766-4.

40. Ishihara S, Yasuda M, Harada I, Mizutani T, Kawabata K, Haga H. Substrate stiffness regulates temporary NF- $\mathrm{B}$ activation via actomyosin contractions. Exp Cell Res. 2013; 319:2916-27.

41. Győrffy B, Surowiak P, Budczies J, Lánczky A. Online survival analysis software to assess the prognostic value of biomarkers using transcriptomic data in non-small-cell lung cancer. PLoS One. 2013; 8:e82241. 